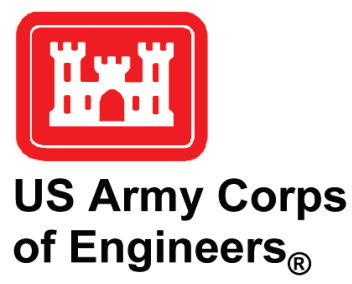

\title{
Coastal Foredune Evolution, Part 2: Modeling Approaches for Meso-Scale Morphologic Evolution
}

\author{
by Margaret L. Palmsten ${ }^{1}$, Katherine L. Brodie ${ }^{2}$, \\ and Nicholas J. Spore ${ }^{2}$
}

PURPOSE: This Coastal and Hydraulics Engineering Technical Note (CHETN) is the second of two CHETNs focused on improving technologies to forecast coastal foredune evolution. Part 1 summarized the short-, meso-, and multi-decadal-timescale environmental factors and forcing processes that influence the morphodynamic evolution of coastal foredunes and described a number of observational studies. Part 2 summarizes the existing approaches used to model foredune evolution and provides a new probabilistic modeling framework that integrates hydrodynamic and aeolian processes to forecast foredune evolution.

INTRODUCTION: As discussed in Part 1, coastal foredunes along developed coastlines are dynamic features that continually evolve in response to changing coastal dynamics, aeolian processes, and management decisions (e.g., Swann et al. 2015). Predicting foredune evolution over time is important to coastal engineers and managers because foredunes provide ecosystem services and can reduce storm damages to coastal infrastructure, both of which increase the resiliency of coastal areas. A recent report documenting dune management challenges on developed coasts (Elko et al. 2016) specifically identified the need to expand both observations and modeling approaches across meso-timescales, which are more directly related to the operational scale of coastal dune and beach management decisions and programs (e.g., over months to decades). The challenge lies in both incorporating significant short-term processes that affect medium- and long-term evolution as well as validating month-to-decadal evolution models with observations. Part 1 of this two-part series summarized the significant processes, controlling factors, and morphologic response on short-, meso-, and multi-decadal-timescales; highlighted significant meso-decadal-timescale observations; and concluded with a summary of significant findings. Part 2 builds upon this knowledge, reviews existing numerical models for dune evolution, and recommends a modeling framework.

STATE-OF-THE-ART DUNE MODELS: As reviewed in Part 1, dune formation and erosion are the result of a number of feedbacks among competing processes. Reflecting the abundance of naturally competing processes, numerous dune models have been developed to address individual aspects of dune morphology evolution. The present state-of-the-art in dune morphology modeling is focused on integrating these models to produce a single model that encompasses dune accretion and erosion processes. Within the discipline of quantitative dune morphodynamic modeling, there are a number of approaches applied including process-based numerical models, parametric models, and probabilistic models. Part 2 first addresses conceptual

\footnotetext{
${ }^{1}$ Naval Research Laboratory, Stennis Space Center, MS

2 U.S. Army Engineer Research and Development Center, Coastal and Hydraulics Laboratory, Duck, NC
} 
models of dune morphology evolution, then parametric models, and then reviews recent developments in integrated approaches to model dune morphodynamics including process-based numerical and probabilistic models, as well as describe several applications of the models.

Conceptual Models. Conceptual models for coastal dune morphology provide the underpinnings for many numerical models as well as a framework for conducting field observations. A number of conceptual models describe aspects of dune geomorphology (e.g., Hesp 2013; Sallenger 2000), whereas Houser et al. (2015) described a more holistic model for dune morphology. Each of these conceptual approaches is described below.

One of the most widely applied conceptual models is the storm impact model of Sallenger (2000), which qualitatively describes the relationship between hydrodynamic forcing and dune response and provides the basis for the process-based numerical model XBeach (Roelvink et al. 2009) and the probabilistic model of Plant and Stockdon (2012). The storm impact model describes four regimes to scale the effect of storm influence on barrier island response. In the swash regime, wave runup does not exceed the base of the dune. In the collision regime, runup exceeds the base of the dune but not the dune crest. In the overwash regime, runup exceeds the crest of the dune. In the inundation regime, the surge level continuously exceeds the elevation of the barrier island. Sallenger (2000) argued that the magnitude and direction of sediment transport are unique for each regime. Stockdon et al. (2007) demonstrated that the storm impact model does have the capability to hindcast the dune response to storm forcing.

Hesp (2013) described the evolution of transgressive dune systems based on visual analysis of coastal dune fields from around the world. He categorized dunes into those with high sediment supply and little vegetation such as in arid climates and those with lower sand supply and more vegetation in temperate and tropical climates. He described the evolution of the backshore dune field including stabilization by vegetation, as well as development of the dune field following erosion events, and the behavior of parabolic dunes.

Houser et al. (2015) described a conceptual model for barrier island equilibrium states, depending on elevation. In the model, storm surge parameters including frequency of occurrence and elevation relative to the island represent a tipping point between barrier islands with high foredunes and those with low, overwash-dominated features. The type and growth rate of vegetation, along with sediment supply, control recovery of dunes and barrier island elevation.

Parametric Models. Parametric models are a quantitative alternative to more simple conceptual models. There is presently no combined parametric model for dune evolution, but there are a number of parametric models available to address different aspects of dune morphodynamics. Here, five parametric models are reviewed that address different aspects of dune erosion and accretion. The models range from time-independent scaling relationships to time-dependent models incorporating simplified physical relationships.

To address dune erosion, Long et al. (2014) identified time-independent scaling relationships that linked the magnitude of dune response to storm characteristics. Specifically, Long et al. (2014) compared the change in elevation of the dune $(\Delta z)$ normalized by the height of the dune $\left(D_{\text {crest }}\right)$ to the difference between the runup height $\left(R_{\text {high }}\right)$ and the dune height $\left(D_{\text {crest }}\right)$ normalized by the significant swash elevation $(S)$ : 


$$
\frac{\Delta z}{D_{\text {crest }}} \sim \frac{\left(R_{\text {high }}-D_{\text {crest }}\right)}{S}
$$

This scaling relationship explained $47 \%-73 \%$ of observed dune erosion for the four storms presented in Long et al. (2014). However, the scaling was not consistent among the individual sites or storms investigated.

Palmsten and Holman (2012) developed a parametric time-dependent model for dune erosion during the collision regime drawing from the wave-impact models of Overton and Fisher (Fisher et al. 1986; Overton and Fisher 1988; Overton et al. 1994a,b) and large-scale laboratory observations of dune erosion. The model relates the volume of sediment eroded from the dune to the elevation of the extreme wave runup, the elevation of the dune base, and the period that the dune is exposed to wave runup as modeled using a normal distribution and the Stockdon et al. (2006) parameterization for wave runup. Splinter and Palmsten (2012) found that this parametric approach required no calibration yet accurately tracked the position of the dune base when used in hindcast mode on field data. Palmsten and Holman (2011) were also able to relate erosion during the collision regime to moisture content of the dune and sediment shear stress.

Three models for dune growth through aeolian transport are discussed next. Baas and Nield (2007) represented vegetated coastal dune growth and migration in the Discrete Ecogeomorphic Aeolian Landscapes model (DECAL) as a cellular automaton, which is an extension of the model for unvegetated dunes developed by Werner (1995). In this approach, simple rules for the probability of sediment transport, angle of repose, and effectiveness of vegetation at reducing the probability of sediment transport are used to model foredune morphodynamics. Baas and Nield (2007) do not make detailed calculations of airflow or sediment transport. The DECAL model qualitatively reproduced vegetated dune landscapes (Baas and Nield 2007; Baas and Nield 2010).

Bauer and Davidson-Arnott (2003) described a modeling framework that includes simple sediment transport equations and schematic beaches to describe the relationship between critical fetch, maximum fetch, beach geometry, and angle of wind approach. Using this highly schematized approach, the sediment transport rate is a tradeoff between increased transport rate into the dune due to longer fetches and decreased transport rate due to more sediment moving parallel to the dune as wind angle relative to the dune increases. The model also incorporates edge effects on sediment transport rate into the dune. However, Bauer and Davidson-Arnott (2003) found that most beaches can be modeled as an infinitely long beach with negligible edge effects, instead of simply dominated by wind angle relative to fetch distance.

Building on the work of Bauer and Davidson-Arnott (2003), Delgado-Fernandez (2011) improved the modeling framework for sediment transport based on fetch, beach geometry, and wind angle by incorporating the supply-limiting effects of moisture content, snow, and ice. Incorporating these effects resulted in better hindcasts of total sediment transport over the study area for the 9-month observation period. Hindcast total transport was of the same order of magnitude as observations and represented a $29 \%$ improvement over neglecting the supply limiting effects. 
Process-Based Numerical Models. Process-based models numerically solve the equations for hydrodynamics and sediment transport that describe dune morphodynamics. Presently, no single process-based model incorporates both dune erosion and accretion, although there are two projects underway to develop erosion/accretion models. Here, these two efforts are reviewed, and a description is provided of a process-based model for cross-shore sediment transport that is incorporated into an operational risk assessment tool.

WindSurf is a process-based dune morphology model presently undergoing development at the Technological University of Delft/Deltares in conjunction with the Building with Nature/ZandMotor project. WindSurf will ultimately combine the eXtreme Beach model (XBeach) (Roelvink et al. 2009), which couples the hydrodynamic effects of waves and currents with morphological changes to the beach, and two models for the effects of aeolian transport on the subaerial beach, Aeolis and the Coastal Dune Model (CDM). The Aeolis model includes an advection diffusion equation taking into account the effects of supply-limited sediment transport on the beach (de Vries et al. 2014). CDM simulates the role of vegetation on controlling foredune crest height (Durán and Moore 2013). The following paragraphs describe the composition of these component models as well as some applications.

XBeach has been widely applied to model storm impacts on beaches. The model was specifically designed to model dune erosion, overwash, and island breaching. Hydrodynamics included in XBeach are directionally spread infragravity wave motions in the surf and swash zone, including wave breaking and wave rollers. Dune erosion is modeled as an avalanching process that, while effective with tuning, is physically unrealistic. Example applications include hindcasting and forecasting, morphologic changes during hurricanes in the United States (e.g., Lindemer et al. 2010; McCall et al. 2010), Bora storms on the Adriatic (e.g., Armaroli et al. 2013; Harley and Ciavola 2013), east coast lows in Queensland, Australia (Splinter and Palmsten 2012), and winter storm erosion (e.g., Baart et al. 2015; Vousdoukas et al. 2012).

Work is underway to couple XBeach with Aeolis for supply-limited sediment transport. Sediment transport in Aeolis is modeled as one-dimensional (1D) advection model where sediment concentration is calculated using a Bagnold-type sediment transport formulation. Sediment concentration is modeled by wind speed to the third power. Erosion is modeled by a pickup function, and deposition depends on sediment concentration. Changes to the sediment bed are limited by the sediment supply rate at the bed. Initial simulations by Aeolis were recently published and compared with linear and nonlinear models for sediment transport (de Vries et al. 2014). Early comparisons between Aeolis simulation and field observations at ZandMotor were presented at American Geophysical Union Ocean Sciences Conference in 2016 and demonstrated the importance of including supply-limited transport in accurately simulating sediment transport.

The second aeolian transport model being coupled to XBeach is CDM. CDM is a variation on a morphodynamic model for desert dunes that has been under development for a number of years (e.g., Durán et al. 2008; Kroy et al. 2002; Weng et al. 1991). CDM expands on the previous versions of the model by incorporating the effect of the presence of water on the threshold shear stress needed for sediment motion and the effect of coast vegetation on threshold shear stress. Durán and Moore (2013) used CDM to identify scale invariant relationships between beach profile and maximum foredune height for incipient and mature dunes. The relationships agreed with a number of observations. Durán and Moore (2013) also found in their model that dune morphology 
was relatively insensitive to details of vegetation growth. Using field data, Durán and Moore (2013) demonstrated that relative dune height correlates with wave height, where wave height controls the distance between the shoreline and the vegetation line, hence the foredune height.

An alternative approach in development at the U.S. Army Corps of Engineers (USACE), Engineer Research and Development Center (ERDC), couples the CShore-C15 (C15) morphology model with a simple vegetation and dry-sand growth model to predict dune growth following overwash events. C15 is a version of the 1D CShore morphology model (Kobayashi et al. 2008), where individual cross-shore profiles that are solved in 1D are allowed to exchange sediment in the alongshore direction driven by gradients in longshore transport. The model accounts for wave and current interaction, bedload and suspended loads, and wave-related sediment transport within the surf and swash zones. C15 is computationally efficient and stable enough for use in a stochastic framework for long simulation periods ${ }^{1}$. While a fully two-dimensional version of CShore termed C2Shore has also been developed and shown to accurately predict dune recession during Hurricane Katrina on Ship Island, Mississippi (Johnson and Grzegorzewski 2011), C15 was developed to simulate longer, management-relevant periods while retaining sediment transport calculations on short timescales (order of seconds). C15 is now being coupled with a heuristic dry-sand dune growth model, a community-based vegetation growth model, and a mechanism for enhanced deposition by aeolian transport over vegetation ${ }^{2}$. The new system is designed to simulate long-term coastal morphological evolution but is untested at present.

One of the earliest process-based models for beach profiles including dunes is Simulating StormInduced Beach Change (SBEACH) (Larson et al. 1990; Larson and Kraus 1989). SBEACH is based on the concept that within the surf zone sediment flux is dependent upon the imbalance between actual energy dissipation and dissipation on an equilibrium beach profile. Linear wave theory and the wave breaking model of Dally et al. (1985) are used to calculate dissipation. Wave setup is calculated as well. Sediment flux increases exponentially from the offshore initiation of sediment movement through wave breaking to the plunge point at the shoreline and then linearly decreases from the plunge point through the swash zone to the limit of wave runup. The sediment transport relations in SBEACH were derived from two prototype scale experiments in large wave tanks. Inputs to SBEACH include an initial beach profile, a description of beach characteristics including grain size, and a time series of offshore wave conditions. SBEACH outputs an updated cross-shore beach profile from gradients in cross-shore sediment transport and can be used to simulate erosion of the primary foredune.

SBEACH was incorporated within Beach- $f x$ by Gravens et al. (2007). Beach- $f x$ provides a framework for evaluating beach nourishment projects and management decisions over multi-year timescales and employs a Monte Carlo simulation of beach change using SBEACH. Boundary conditions for SBEACH are based on historical environmental forcing for the study site. The Monte Carlo simulations incorporate uncertainty in model parameters and environmental forcing. A major advantage of Beach- $f x$ is its probabilistic approach through Monte Carlo simulation, which is useful for decision making. While Beach- $f x$ attempts to predict potential dune erosion over meso-timescales, it presently has no mechanism that allows for dune growth over similar timescales.

\footnotetext{
${ }^{1}$ B. Johnson and J. McNinch, ERDC/CHL, personal communication, May 2016.

2 B. Johnson, ERDC/CHL, and C. Piercy, ERDC/EL, personal communication, May 2016.
} 
Probabilistic Models. Data-driven probabilistic models are an alternative to deterministic models, and significant literature exists regarding their applicability to dune erosion. There are several advantages to applying a probabilistic model. In particular, probabilistic models have low computational cost and inherently include an uncertainty estimate for decision-making. Plant and Stockdon (2012) developed the first probabilistic model for predicting dune morphodynamics. Their approach was to quantify and extend the conceptual storm impact model of Sallenger (2000) using a Bayesian Network (BN), which would be trained using two sources of data. Lidar observations of foredune morphology on Santa Rosa Island, FL, before and after Hurricane Ivan in 2004 were included in the BN. Tide, surge, wave height, and wavelength included in the BN were hindcast using Delft3D, and wave runup at the shore was calculated using the parameterization of Stockdon et al. (2006). In addition to dune-crest elevation, dune-base elevation, dune-crest elevation change, surge height, and runup height included in the Sallenger (2000) storm impact model, the BN included dune width, beach width, dune position change, and shoreline change. Using this approach, Plant and Stockdon (2012) accurately hindcasted dune change for Hurricane Ivan. Palmsten et al. (2014) adapted the model of Plant and Stockdon (2012) for use on the Gold Coast of Queensland, AU, to hindcast dune retreat distance. Palmsten et al. (2013) demonstrated that a Bayesian network developed at one geographic location can be applied at a second location, given similar morphology and similar hydrodynamic forcing.

PROBABILISTIC DUNE EVOLUTION MODEL: The authors propose a probabilistic model for dune evolution combining the approach of Plant and Stockdon (2012) to model dune erosion due to the impacts of storm surge and waves with the framework described by DelgadoFernandez (2011) to model dune accretion due to aeolian processes. The framework described by Delgado-Fernandez (2011) will be incorporated into the BN design developed by Plant and Stockdon (2012) (Figure 1). The new BN dune model will incorporate morphological variables including dune-crest elevation, dune-base elevation, dune width, and beach width. Hydrodynamic variables will include surge height, runup height, and moisture content. Aeolian variables will include wind speed, wind direction, fetch distance (which depends upon the distance between the shoreline and the vegetation line), and critical fetch distance. Variables describing the duration of hydrodynamic and aeolian forcing events will be included in the network, and the network will be forced with time-dependent forcing for hindcasts and forecasts.

In this new BN dune model, variables are represented as probability distributions of prior observations. Arrows linking the variables (Figure 1) represent the joint probabilities between variables. The joint probability distributions between variables will be learned using the Expectation-Maximization (EM) algorithm, a widely used machine learning technique (e.g., Moon 1996). The necessary data will be obtained to train the network with a nearly 30 -year record of variables from hydrodynamic, morphologic, meteorological, and Argus video imagery data collected at the ERDC Coastal and Hydraulics Laboratory (CHL), Field Research Facility (FRF) in Duck, NC. This approach will be used to evaluate the sensitivity of dune erosion to input variables and to test the hypothesis that dune building at the FRF occurs during windy, low-moisture conditions when wind direction is oblique to the dune line. Once sensitivity is analyzed for dunes at the FRF, the data will be incorporated from other sites to test the applicability of the relationships that are identified. The new $\mathrm{BN}$ approach described here could integrate with existing models, which can provide time-dependent forcing to the network. Additionally, the new BN dune model can be integrated with Beach- $f x$ to be used as a tool for risk analysis and decision making. 


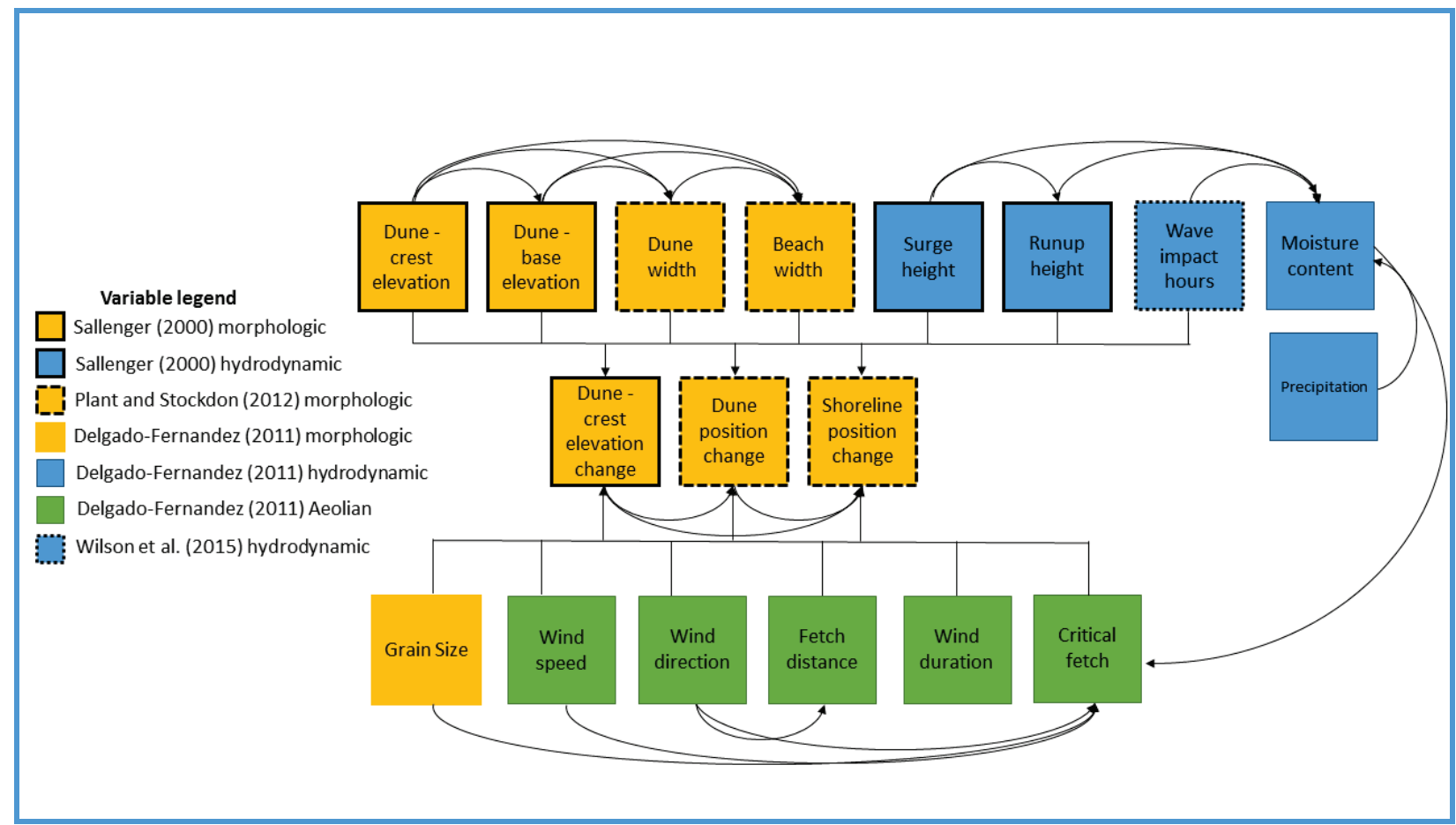

Figure 1. Schematic diagram of the new Bayesian network for dune evolution. Boxes represent probability distributions of variables, and black arrows represent the joint probabilities between variables. Yellow boxes are morphological variables, green boxes are aeolian variables, and blue boxes are hydrodynamic variables. Boxes outlined in solid black are variables included in the Sallenger (2000) storm impact model. Boxes outlined in the dashed black line represent the extended Bayesian Network model of Plant and Stockdon (2012). Boxes without outlines represent variables in the Delgado-Fernandez (2011) framework. The box outlined in the black dotted line represents a hydrodynamic variable from the Bayesian network of Wilson et al. (2015).

SUMMARY OF FINDINGS: Developing a predictive capability for foredune evolution that incorporates dune growth and erosion processes is important to coastal engineers and managers because understanding the natural ability of foredunes to rebuild post-storm can help improve the management of dunes and, ultimately, the ability to quantify the resiliency of coastal areas. The probabilistic modeling framework developed in this technical note is based on observations of foredune morphodynamics (discussed in Part 1) and existing models. Significant findings from Part 2 are summarized below.

- Foredune morphology depends on the feedback between hydrodynamic and aeolian processes, yet no single model presently exists that combines both types of processes.

- The relationships between beach morphologic characteristics including elevation of the dune base and dune crest, dune width, beach width, and hydrodynamic forcing including surge and wave runup are the basis for most conceptual, parametric, numerical, and probabilistic models for dune erosion.

- The relationships between beach morphologic characteristics including dune elevation, beach width, and grain size; aeolian characteristics including wind speed, wind direction, and fetch distance; and hydrodynamic characteristics including moisture content and precipitation are the basis for most conceptual, parametric, numerical, and probabilistic models for dune accretion. 
- Incorporating the effects of time-dependent changes to morphology is an essential part of all models for foredune evolution.

- A new probabilistic modeling framework was designed with the aim of developing a predictive capability for foredune evolution over short-, meso-, and multi-decadaltimescales due to both hydrodynamic and aeolian processes. This model will be initially tested and evaluated using 30 years of data collected at CHL's FRF in Duck, NC. Finally, there will be an evaluation of the sensitivity of the model to each variable.

ADDITIONAL INFORMATION: For additional information, contact Katherine L. Brodie, Coastal Observation and Analysis Branch, Coastal and Hydraulics Laboratory, 1261 Duck Rd, Duck, NC, 27949 at 252-261-6840 x233 or email: Katherine.L.Brodie@usace.army.mil. This research was initiated and funded by the USACE Coastal Inlets Research Program in response to Statements of Need 2014-N-11, "Guidance and Tools Needed to Calculate Integrated Coastal Resilience," and 2015-N-11, "Develop Guidance for Coastal Resilience." This CHETN should be cited as follows:

Palmsten, M. L., K. L. Brodie, and N. J. Spore. 2017. Coastal foredune evolution, Part 2: Modeling approaches for meso-scale morphologic evolution. ERDC/CHL CHETN-II-57. Vicksburg, MS: U.S. Army Engineer Research and Development Center. http://dx.doi.org/10.21079/11681/21627.

\section{REFERENCES}

Armaroli, C., E. Grottoli, M. D. Harley, and P. Ciavola. 2013. Beach morphodynamics and types of foredune erosion generated by storms along the Emilia-Romagna coastline, Italy. Geomorphology 199:22-35.

Baart, F., M. van Ormondt, J. S. M. van Thiel de Vries, and M. van Koningsveld. 2015. Morphological impact of a storm can be predicted three days ahead. Comput. Geosci. 90(part b):17-23.

Baas, A. C. W., and J. M. Nield. 2007. Modelling vegetated dune landscapes. Geophysical Research Letters 34(6): $\mathrm{n} / \mathrm{a}-\mathrm{n} / \mathrm{a}$.

Baas, A. C. W., and J. M. Nield. 2010. Ecogeomorphic state variables and phase-space construction for quantifying the evolution of vegetated aeolian landscapes. Earth Surface Processes and Landforms 35(6):717-731.

Bauer, B. O., and R. G. D. Davidson-Arnott. 2003. A general framework for modeling sediment supply to coastal dunes including wind angle, beach geometry, and fetch effects. Geomorphology 49(1-2):89-108.

Dally, W. R., R. G. Dean, and R. A. Dalrymple. 1985. Wave height variation across beaches of arbitrary profile. Journal of Geophysical Research: Oceans 90(C6):11917-11927.

Delgado-Fernandez, I. 2011. Meso-scale modelling of aeolian sediment input to coastal dunes. Geomorphology 130(3-4):230-243.

de Vries, S., J. S. M. van Thiel de Vries, L. C. van Rijn, S. M. Arens, and R. Ranasinghe. 2014. Aeolian sediment transport in supply limited situations. Aeolian Research 12:75-85.

Durán, O., and L. J. Moore. 2013. Vegetation controls on the maximum size of coastal dunes. Proceedings of the National Academy of Sciences 110(43):17217-17222.

Durán, O., M. V. N. Silva, L. J. C. Bezerra, H. J. Herrmann, and L. P. Maia. 2008. Measurements and numerical simulations of the degree of activity and vegetation cover on parabolic dunes in north-eastern Brazil. Geomorphology 102(3-4):460-471. 
Elko, N., K. Brodie, H. Stockdon, K. Nordstrom, C. Houser, K. McKenna, L. Moore, J. Rosati, P. Ruggiero, R. Thuman, and I. Walker. 2016. Dune management challenges on developed coasts. Shore \& Beach 84(1):15.

Fisher, J. S., M. F. Overton, and T. Chisholm. 1986. Field measurements of dune erosion. 20th International Conference on Coastal Engineering, Taipei, Taiwan, Chapter 82, No. 20, 1107-1115. New York: American Society of Civil Engineers.

Gravens, M. B., R. M. Males, and D. A. Moser. 2007. Beach-fx: Monte carlo life-cycle simulation model for estimating shore protection project evolution and cost benefit analyses. Shore and Beach 75(1):19-12.

Harley, M. D., and P. Ciavola. 2013. Managing local coastal inundation risk using real-time forecasts and artificial dune placements. Coastal Engineering 77(0):77-90.

Hesp, P. A. 2013. Conceptual models of the evolution of transgressive dune field systems. Geomorphology 199:138-149.

Houser, C., P. Wernette, E. Rentschlar, H. Jones, B. Hammond, and S. Trimble. 2015. Post-storm beach and dune recovery: Implications for barrier island resilience. Geomorphology 234:54-63.

Johnson, B. and Grzegorzewski, A.S. 2011. Modeling nearshore morphologic evolution of Ship Island during Hurricane Katrina. In Proceedings 7th International Symposium on Coastal Engineering and Science of Coastal Sediment Processes, 1797-1810.

Kobayashi, N., A. Payo, and L. Schmied. 2008. Cross-shore suspended sand and bedload transport on beaches. Journal of Geophysical Research 113(C07001). doi:10.1029/2007JC004203.

Kroy, K., G. Sauermann, and H. J. Herrmann. 2002. Minimal model for sand dunes. Physical Review Letters 88(5):054301.

Larson, M., N. Kraus, and M. Byrnes. 1989. Sbeach: Numerical model for simulating storm-induced beach change, report 1. Technical Report CERC-89-9. Vicksburg, MS: Waterways Experiment Station, Army Corps of Engineers Coastal Engineering Research Center.

Larson, M., N. Kraus, and M. Byrnes. 1990. Sbeach: Numerical model for simulating storm-induced beach change, report 2. Technical Report CERC-89-9. Vicksburg, MS: Waterways Experiment Station, Army Corps of Engineers Coastal Engineering Research Center.

Lindemer, C. A., N. G. Plant, J. A. Puleo, D. M. Thompson, and T. V. Wamsley. 2010. Numerical simulation of a low-lying barrier island's morphological response to Hurricane Katrina. Coastal Engineering 57(11-12):985995.

Long, J. W., A. T. M. de Bakker, and N. G. Plant. 2014. Scaling coastal dune elevation changes across storm-impact regimes. Geophysical Research Letters 41(8):2899-2906.

McCall, R. T., J. S. M. Van Thiel de Vries, N. G. Plant, A. R. Plant, A. R. Van Dongeren, J. A. Roelvink, D. M. Thompson, and A. J. H. M. Reniers. 2010. Two-dimensional time dependent hurricane overwash and erosion modeling at Santa Rosa Island. Coastal Engineering 57(7):668-683.

Moon, T. K. 1996. The expectation-maximization algorithm. IEEE Signal Processing Magazine 13(6):47-60.

Overton, M. F., and J. S. Fisher. 1988. Simulation modeling of dune erosion. International Conference on Coastal Engineering, Costa del Sol-Malaga, Spain, 1857-1867, New York, NY.

Overton, M. F., J. S. Fisher, and K. N. Hwang. 1994a. Development of a dune erosion model using supertank data. Proceedings of the Twenty-Fourth International Conference on Coastal Engineering, Kobe Japan, 2488-2502.

Overton, M. F., W. A. Pratikto, J. C. Lu, and J. S. Fisher. 1994b. Laboratory investigation of dune erosion as a function of sand grain-size and dune density. Coastal Engineering 23(1-2):151-165. 
Palmsten, M. L., and R. A. Holman. 2011. Infiltration and instability in dune erosion. Journal of Geophysical Research: Oceans 116(C10):C10030.

Palmsten, M. L., and R. A. Holman. 2012. Laboratory investigation of dune erosion using stereo video. Coastal Engineering 60(0):123-135.

Palmsten, M. L., K. T. Holland, and N. G. Plant. 2013. Velocity estimation using a bayesian network in a criticalhabitat reach of the Kootenai River, Idaho. Water Resources Research 49(9):5865-5879.

Palmsten, M. L., K. D. Splinter, N. G. Plant, and H. Stockdon. 2014. Probabilistic estimation of dune retreat on the Gold Coast, Australia. Shore \& Beach 82(4):35-43.

Plant, N. G., and H. F. Stockdon. 2012. Probabilistic prediction of barrier-island response to hurricanes. Journal of Geophysical Research 117(F3):F03015.

Roelvink, D., A. Reniers, A. van Dongeren, J. van Thiel de Vries, R. McCall, and J. Lescinski. 2009. Modelling storm impacts on beaches, dunes and barrier islands. Coastal Engineering 56(11-12):1133-1152.

Sallenger, A. H., Jr. 2000. Storm impact scale for barrier islands. Journal of Coastal Research 16(3):890-895.

Splinter, K. D., and M. L. Palmsten. 2012. Modeling dune response to an east coast low. Marine Geology 329331(0):46-57.

Stockdon, H. F., R. A. Holman, P. A. Howd, and A. H. Sallenger. 2006. Empirical parameterization of setup, swash, and runup. Coastal Engineering 53(7):573-588.

Stockdon, H. F., J. A. H. Sallenger, R. A. Holman, and P. A. Howd. 2007. A simple model for the spatially-variable coastal response to hurricanes. Marine Geology 238(1-4):1-20.

Swann, C., K. L. Brodie, and N. Spore. 2015. Coastal foredunes:identifying coastal, aeolian, and management interactions driving morphologic state change. ERDC/CHL TR-15-17. Vicksburg, MS: U.S. Army Engineer Research and Development Center.

Vousdoukas, M., Ó. Ferreira, L. Almeida, and A. Pacheco. 2012. Toward reliable storm-hazard forecasts: Xbeach calibration and its potential application in an operational early-warning system. Ocean Dynamics 62(7):10011015.

Weng, W. S., J. C. R. Hunt, D. J. Caruthers, A. Warren, G. F. S. Wiggs, I. Livingstone, and I. Castro. 1991. Air flow and sand transport over sand-dunes. In Aeolian grain transport: The erosional environment. Edited by $\mathrm{O}$. E. Barndorff-Nielsen and B. B. Willetts, 1-22. Vienna: Springer Vienna.

Werner, B. T. 1995. Eolian dunes: Computer simulations and attractor interpretation. Geology 23(12):1107-1110.

Wilson, K. E., P. N. Adams, C. J. Hapke, E. E. Lentz, and O. Brenner. 2015. Application of Bayesian networks to hindcast barrier island morphodynamics. Coastal Engineering 102:30-43.

NOTE: The contents of this technical note are not to be used for advertising, publication, or promotional purposes. Citation of trade names does not constitute an official endorsement or approval of the use of such products. 